\title{
Efeito de Pontas de Pulverização e de Arranjos Populacionais DE PlantAS DE Eichhornia crassipes E Salvinia auriculata NA Deposição de Calda de Pulverização sobre Plantas de Pistia stratiotes ${ }^{1}$
}

\author{
Effect of Spray Tips and Water Hyacinth and Water Lettuce Plant Population Arrangements of \\ Watermoss Plant Spray Mix Deposition
}

\author{
MARCHI, S.R. ${ }^{2}$, MARTINS, D. ${ }^{3}$, COSTA, N.V. ${ }^{4}$, DOMINGOS, V.D. ${ }^{4}$ e CARDOSO, L.A. ${ }^{4}$
}

\begin{abstract}
RESUMO - Este trabalho teve por objetivo avaliar o depósito de calda pulverizada por dois tipos de pontas de pulverização sob plantas de alface-d'água (Pistia stratiotes) dispostas em diferentes arranjos populacionais com plantas de aguapé (Eichhornia crassipes) e salvinia (Salvinia auriculata). Para isso, foi conduzido um experimento em condições de caixas-d'água em delineamento experimental inteiramente casualizado, com quatro repetições. Os tratamentos estiveram dispostos em esquema fatorial $2 \times 8$, sendo dois tipos de pontas de pulverização (ConeJet TXVK-8 e TeeJet DG 11002 VS) e oito proporções entre as plantas aquáticas, a saber: dominância total da área correspondente a $100 \%$ de cobertura da caixad'água pelas plantas de alface-d'água; e as proporções entre plantas de alface-d'água e plantas de aguapé ou salvinia a 75\%:25\%, 50\%:50\% e 25\%:75\%. Também foi utilizada uma densidade tripla, na qual as três espécies estiveram igualmente dispostas na proporção de 33,33\%. Soluções dos corantes Amarelo Tartrasina FDC-5 a 3.500 ppm e Azul Brilhante FDC-1 a 1.000 ppm foram utilizadas como traçadores para as pontas TXVK-8 e DG 11002VS, respectivamente. A pulverização de ambas as soluções foi efetuada na mesma unidade experimental, com um intervalo de 30 minutos entre si, utilizando-se um pulverizador costal pressurizado com $\mathrm{CO}_{2}$, calibrado de modo a proporcionar um volume de aplicação aproximado de 200 L ha. Apốs a pulverização, as plantas presentes nos reservatórios foram lavadas com água destilada, até remoção total dos corantes. Os depósitos totais de calda foram estimados em $\mu \mathrm{L}$ por planta, e os depósitos unitários, em $\mu \mathrm{L} \mathrm{cm}^{-2}$ de superfície foliar. O aumento na proporção de plantas de aguapé na associação proporcionou menores depósitos de calda de pulverização sobre as plantas de alface-d'água. Em contrapartida, o aumento na proporção de salvinia na associação propiciou maiores depósitos de calda de pulverização, independentemente do tipo de ponta de pulverização. A ponta TXVK-8 proporcionou depósitos unitários e totais de calda de pulverização superiores aos da ponta DG 11002VS.
\end{abstract}

Palavras-chave: deposição de gotas, SAVAU, EICCH, PISST, tecnologia de aplicação.

ABSTRACT - This study aimed to evaluate two types of nozzles (ConeJet TXVK-8 and TeeJet DG 11002 VS) and the amount of spray mix deposited on water lettuce (Pistia stratiotes) plants organized under different population arrangements with water hyacinth (Eichhornia crassipes) and eared watermoss (Salvinia auriculata) plants. In addition to a full-dominance proportion over the area, corresponding to $100 \%$ cover of the water tank by eared watermoss plants, arrangements were used with either water hyacinth or water lettuce at 75\%:25\%, 50\%:50\%, and 25\%:75\%. Triple density was also used, with the three species being equally displayed at a 33.33\% proportion. Dye solutions of FD\&C Yellow no. 5 at 3,500 ppm and FD\&C Blue no. 1 at 1,000 ppm were used as spraying tracers for TXVK-8 and DG 11002 VS nozzles, respectively.

1 Recebido para publicação em 11.7.2008 e na forma revisada em 5.6.2009.

2 Prof. Adjunto Agronomia IUNMAT/UFMT - campus de Sinop, Av. Alexandre Ferronatto 1200, 78550-000 Sinop-MT, <sidneimarchi.ufmt@gmail.com>; ${ }^{3}$ Professor Livre-Docente do Dep. de Produção Vegetal/Agricultura, FCA/UNESP, Botucatu-SP; ${ }^{4}$ Engo - -Agr ${ }^{0}$, Doutorando em Agricultura, Dep. de Produção Vegetal/Agricultura, FCA/UNESP. 
Both solutions were sprayed at the same plot within 30 minute interval each through a $\mathrm{CO}_{2}$ pressured backpack knapsack calibrated to deliver a spray volume around $200 \mathrm{~L} \mathrm{ha-1}$. Plants at reservoirs were flushed with distilled water until total removal of the dyes deposited on them. The total spray deposits were estimated in $\mu \mathrm{L}$ per plant and the unitary deposits where estimated in $\mu \mathrm{L} \mathrm{cm}^{-2}$ of foliar surface. Increase in water hyacinth plant proportion in the arrangement resulted in lower spray deposition over water lettuce. Increase in water moss plant proportion in the arrangement provided higher spray depositions over water lettuce, independently of the nozzle type used. The TXVK-8 nozzles provided higher unitary and total spray depositions compared to the DG 11002 VS nozzle.

Keywords: drop deposition, PISST, EICCH, SAVAU, spraying technology.

\section{INTRODUÇÃO}

Uma grande diversidade de plantas aquáticas pode ser encontrada vegetando as margens de rios e reservatórios ou dentro dos mais diversos ambientes aquáticos, empregando diferentes mecanismos de adaptação para sobrevivência e desenvolvimento. Enquanto algumas espécies apresentam-se enraizadas em corpos d'água com fortes correntezas, outras somente podem viver em águas paradas ou estagnadas.

Entre as principais plantas daninhas aquáticas, podem-se destacar E. crassipes, $P$. stratiotes, Echinochloa polystachya, espécies aquáticas dos gêneros Polygonum e Salinia, Brachiaria subquadripara, Typha dominguensis, Egeria densa, Egeria najas e espécies aquáticas do gênero Cyperus (Martins et al., 2002). Contudo, as plantas daninhas aquáticas flutuantes são as que causam os mais sérios e difundidos problemas em nível mundial. Estas normalmente apresentam rápida capacidade de multiplicação vegetativa, independência das estruturas sexuais de reprodução, grande área de tecido fotossintético em proporção ao comprimento da planta, rápida capacidade de ocupar locais disponiveis onde incida luz, além da independência das condições do substrato, devido ao fluxo d'água e à localização das plantas (Holm et al., 1991; Kissmann \& Groth, 1997).

P. stratiotes (alface-d'água), pertencente à família Araceae, é uma espécie flutuante que apresenta capacidade de rápida multiplicação vegetativa, habilidade para regenerar-se a partir de pequenas porções do talo e independência parcial ou completa das estruturas sexuais de reprodução. A planta nova dirige sua energia para o desenvolvimento de folhas, e a planta mais velha dirige a energia para o desenvolvimento de estolões (Kissmann \& Groth, 1997).

Geralmente, P. stratiotes, E. crassipes e $S$. auriculata são facilmente encontradas associadas nas diversas populações de plantas aquáticas, pois essas três espécies apresentam praticamente a mesma preferência quanto às condições ambientais (Holm et al., 1991). Levantamentos realizados em comunidades de plantas aquáticas nos reservatórios da Companhia Energética de São Paulo mostraram que $P$. stratiotes, E. crassipes e $S$. auriculata sempre estiveram citadas entre as seis espécies de plantas aquáticas mais frequentes (Tanaka et al., 2002; Martins et al., 2003; Carvalho et al., 2003, 2005; Cavenaghi et al., 2005). Entretanto, plantas de aguapé são altamente competitivas, tendendo a dominar o ambiente aquático e prevalecendo sobre plantas como Azolla sp., P. stratiotes, Salvinia spp. etc. (Kissmann \& Groth, 1997).

Entre os possiveis métodos aplicáveis para o controle de plantas aquáticas, o método químico através da utilização de herbicidas surge como uma opção econômica e eficaz para o manejo dessas plantas. Vários trabalhos realizados por diferentes pesquisadores têm comprovado a eficiência do controle químico nessas plantas flutuantes e sua segurança sobre organismos aquáticos por meio do uso de diversos herbicidas, como 2,4-D (Joyle \& Sikka, 1977; Selvan \& Lall, 1981; Martins et al., 1999, 2002; Nelson \& Shearer, 2005), glyphosate (Van et al., 1987; Martins et al., 1999; Lindgren et al., 1999; Neves et al., 2002; Martins et al., 2002; Fairchild et al., 2002), diquat (Martins et al., 1999, 2002), imazapyr 
(Martins et al., 1999, 2002), carfentrazoneethyl (Koschnick et al., 2004), entre outros.

Entretanto, controles insatisfatórios têm sido observados em experimentos de campo e provavelmente podem ser atribuídos à falta de um contato apropriado do produto com as plantas (Martins et al., 2002; Neves et al., 2002). Nesse sentido, o tipo de ponta utilizada na pulverização, a presença e o arranjo entre plantas podem influenciar a quantidade dos depósitos de calda pulverizada sobre as plantas de alface-d'água, uma vez que a posição do limbo foliar, em relação à posição daquele das plantas vizinhas, pode favorecer ou prejudicar o contato entre a gota e a superficie da folha.

Teoricamente, folhas dispostas em posição vertical superior são mais eficientes na captura de gotas que aquelas orientadas em posição vertical inferior - o chamado "efeito guarda-chuva" (Spillman, 1984; Wirth et al., 1991; Gerard et al., 1998; Richardson \& Newton, 2000). Esse pode ser um fator determinante na deposição de calda em plantas de alface-d'água que convivem associadas com plantas de aguapé e salvínia. Uma forma de melhorar a deposição de calda de pulverização seria o uso de pontas que produzam maior dinâmica na gota, como as do tipo cone.

Apesar de existirem pesquisas que avaliem a eficiência dos herbicidas, ainda há pouca informação no que diz respeito à tecnologia de aplicação em ambientes aquáticos, e praticamente são inexistentes informações referentes à quantificação da calda de pulverização depositada em plantas aquáticas convivendo em ambiente comum.

Este trabalho teve o objetivo de quantificar os depósitos de calda de pulverização proporcionados pelas pontas TXVK-8 e DG 11002VS sobre plantas de $P$. stratiotes dispostas em diferentes arranjos populacionais com plantas de E. crassipes e $S$. auriculata.

\section{MATERIAL E MÉTODOS}

O presente trabalho foi conduzido no NUPAM (Núcleo de Pesquisas Avançadas em Matologia), pertencente ao Departamento de Produção Vegetal, setor de Agricultura da FCA/UNESP - campus de Botucatu-SP. O experimento foi conduzido no delineamento inteiramente casualizado com quatro repetições, adotando-se o esquema fatorial $2 \times 8$, no qual foram estudados os depósitos de calda de pulverização proporcionados por dois tipos distintos de ponta de pulverização, em oito diferentes arranjos populacionais de plantas aquáticas. As unidades experimentais foram constituídas de caixas plásticas com dimensões de $45 \times 60$ × $60 \mathrm{~cm}$ e sem nenhum tipo de substrato depositado no fundo. As diferentes proporções utilizadas foram estabelecidas segundo a quantidade máxima de plantas suficiente para preencher totalmente a área superficial da unidade experimental.

Para facilitar a distribuição das plantas nos arranjos duplos, os reservatórios foram divididos em quatro quadrantes de iguais medidas, nos quais as espécies aquáticas eram retiradas ou então incluídas na associação. Após serem estabelecidas as proporções dentro dos quadrantes, as plantas foram misturadas entre si até obter distribuição aleatória dentro dos reservatórios. Esse procedimento foi realizado sete dias antes da aplicação dos corantes, com o objetivo de permitir a total decantação de materiais provenientes do sistema radicular, além de proporcionar a plena estabilização das plantas dentro das caixas-d'água.

As espécies utilizadas neste estudo foram alface-d'água, aguapé e salvínia, cujas áreas foliares médias avaliadas foram de 138,48, 221,07 e $21,27 \mathrm{~m}^{2}$ por planta, respectivamente. Os arranjos populacionais (ou proporções) foram obtidos através da combinação entre plantas de alface-d'água e as outras duas espécies no mesmo reservatório.

Também foi incluído um tratamento composto por um arranjo populacional triplo, no qual as plantas aquáticas estiveram igualmente dispostas na proporção de 33,33\%. As proporções e quantidades de plantas aquáticas por unidade experimental estão apresentadas na Tabela 1.

A pulverização foi realizada com pulverizador costal pressurizado com $\mathrm{CO}_{2}$, contendo barra de aplicação equipada com duas pontas de pulverização, espaçadas de $50 \mathrm{~cm}$ entre si. Foram avaliados dois tipos de pontas: jato cônico ConeJet TXVK-8 e jato plano TeeJet DG $11002 \mathrm{VS}$. O equipamento foi individualmente calibrado para as duas pontas, visando um 
Tabela 1 - Arranjos populacionais, proporções e número de plantas aquáticas utilizadas nas caixas-d'água para o estudo de deposição de calda de pulverização. Botucatu-SP, 2004

\begin{tabular}{|l|c|c|c|c|}
\hline \multirow{2}{*}{ Arranjo } & \multirow{2}{*}{ Proporção (\%) } & \multicolumn{3}{c|}{ Número de plantas por caixa } \\
\cline { 3 - 5 } & & Alface-d'água & Aguapé & Salvínia \\
\hline Alface-d'água & 100 & 28 & 0 & 0 \\
\hline Alface-d'água/aguapé & $75 / 25$ & 21 & 4 & 0 \\
\hline Alface-d'água/aguapé & $50 / 50$ & 14 & 8 & 0 \\
\hline Alface-d'água/aguapé & $25 / 75$ & 7 & 12 & 0 \\
\hline Alface-d'água/salvínia & $75 / 25$ & 21 & 0 & 45 \\
\hline Alface-d'água/salvínia & $50 / 50$ & 14 & 0 & 90 \\
\hline Alface-d'água/salvínia & $25 / 75$ & 10 & 05 & 135 \\
\hline Alface-d'água/aguapé/salvínia & $33,3 / 33,3 / 33,3$ & & 0 \\
\hline
\end{tabular}

consumo de calda de $200 \mathrm{~L} \mathrm{ha}^{-1}$, adotandose o mesmo sentido de deslocamento para ambas as pulverizações. Os corantes, os consumos médios de calda de pulverização obtidos após a calibração de cada tipo de ponta e as condições climáticas observadas durante as aplicações estão apresentados na Tabela 2.

Soluções do corante Amarelo Tartrasina FDC- 5 e do corante Azul Brilhante FDC- 1 foram utilizadas como traçadores para as pontas de pulverização, uma vez que a aplicação com ambas as pontas de pulverização foi efetuada na mesma unidade experimental, com o objetivo de estudar quantitativamente a calda depositada nas distintas situações de pulverização em alvo único.

Tabela 2 - Corantes, consumo médio de calda de pulverização obtido após a calibração das pontas de pulverização e condições climáticas observadas durante as aplicações. Botucatu-SP, 2004

\begin{tabular}{|l|c|c|}
\hline \multirow{2}{*}{\multicolumn{1}{|c|}{ Parâmetro }} & \multicolumn{2}{c|}{ Ponta } \\
\cline { 2 - 3 } & TXVK-8 & DG 11002VS \\
\hline Classe de gotas & Amarelo Tartrasina FDC-5 & Azul Brilhante FDC-1 \\
\hline Corante & $201,9 \mathrm{~L} \mathrm{ha}^{-1}$ & $201,5 \mathrm{~L} \mathrm{ha}{ }^{-1}$ \\
\hline Consumo médio de calda & $3,0 \mathrm{bar}$ & $2,0 \mathrm{bar}$ \\
\hline Pressão de trabalho & $01 / 07 / 2004$ & $01 / 07 / 2004$ \\
\hline Data aplicação & $8: 30 \mathrm{~h}$ & $9: 05 \mathrm{~h}$ \\
\hline Hora aplicação & $21,4^{\circ} \mathrm{C}$ & $21,2{ }^{\circ} \mathrm{C}$ \\
\hline Temperatura do ar & $63 \%$ & $66^{\circ} \%$ \\
\hline Umidade relativa do ar & $3,1 \mathrm{~km} \mathrm{~h}^{-1}$ & $3,3 \mathrm{~km} \mathrm{~h}^{-1}$ \\
\hline Velocidade do vento & $90^{\circ}$ & $90^{\circ}$ \\
\hline Ângulo jato pulverização & & \\
\hline
\end{tabular}

Adotou-se intervalo de 30 minutos entre pulverizações, o que possibilitou a secagem das gotas na superfície das folhas e possiveis perdas por escorrimento da calda depositada. Deve-se ressaltar que esses corantes não influem nas características fisicas da calda, como a tensão superficial das gotas pulverizadas (Carbonari et al., 2005; Souza et al., 2007), e não são absorvidos pelas folhas ou degradados pela luz solar por um período de até oito horas após a aplicação (Marchi et al., 2005a).

Imediatamente após a aplicação das caldas de pulverização, procedeu-se à coleta e lavagem das plantas com água destilada, para retirada e recuperação dos corantes que eventualmente tenham sido depositados durante as respectivas aplicações. As plantas foram lavadas separadamente, utilizando-se $50 \mathrm{~mL}$ de água destilada para cada uma delas. As amostras obtidas foram acondicionadas em frascos plásticos de cor âmbar devidamente etiquetados e armazenados ao abrigo do calor e da luz. Posteriormente, procedeu-se a leituras de absorbância em todas as amostras obtidas com auxílio de espectrofotômetro de feixe duplo, modelo CGB Cintra 20, operando com $10 \mathrm{~mm}$ de caminho ótico no comprimento de onda de $630 \mathrm{~nm}$ para o corante Azul Brilhante FDC-1 e $427 \mathrm{~nm}$ para o corante Amarelo Tartrasina FDC-5. Os dados de absorbância foram transformados em $\mathrm{ppm}$ por equação matemática obtida pela leitura da absorbância de diferentes soluções-padrão de ambos os corantes, cujas concentrações (em $\mathrm{ppm}$ ) foram previamente estipuladas. 
Conhecendo as diferentes concentrações das amostras obtidas, foi possivel chegar ao volume de calda de pulverização depositada nas plantas por meio da expressão matemática $\mathrm{C} 1 . \mathrm{V} 1$ = C2.V2, em que:

$\mathrm{C} 1$ - concentração da calda de pulverização, em ppm, no momento da aplicação;

$\mathrm{V} 1$ - quantidade em $\mathrm{mL}$ que depositou nas plantas;

C2 - concentração da amostra, em ppm; e

$\mathrm{V} 2$ - quantidade em $\mathrm{mL}$ de água destilada utilizada na lavagem.

O produto dessa expressão matemática foi multiplicado por 1.000 para obtenção do volume em $\mu \mathrm{L}$. Os resultados em $\mu \mathrm{L}$ foram divididos pelas áreas foliares ou pela biomassa seca das plantas, tendo sido obtidas as quantidades de calda de pulverização depositada em $\mu \mathrm{L} \mathrm{cm}^{-2}$ e $\mu \mathrm{L}$ por planta nos diferentes arranjos estudados, respectivamente.

A área foliar das plantas de alface-d'água (AS) foi determinada pela equação de estimativa AS $=0,9426(\mathrm{C} \times \mathrm{L})$, em que $\mathrm{C}=$ comprimento ao longo da nervura principal; e $\mathrm{L}=$ largura máxima perpendicular à nervura principal (Marchi et al., 2004).

Após obtenção da área foliar, as plantas foram acondicionadas em sacos de papel e colocadas em estufa de circulação forçada de ar a uma temperatura de $60{ }^{\circ} \mathrm{C}$, até que atingissem peso constante. Posteriormente, foram pesadas em balança de precisão e obtidas as respectivas biomassas secas.

Os resultados das quantidades de calda de pulverização depositadas nas plantas foram submetidos à análise de variância pelo teste $\mathrm{F}$, e as médias dos tratamentos, comparadas pelo teste de Tukey a $5 \%$ de probabilidade.

\section{RESULTADOS E DISCUSSÃO}

Os valores médios dos depósitos unitários de calda de pulverização proporcionados pelas pontas TXVK-8 e DG 11002VS sobre as plantas de $P$. stratiotes estão apresentados na Tabela 3. Exceto para a proporção de $25 \%$ de alface-d'água e $75 \%$ de aguapé, os depósitos unitários médios $\left(\mu \mathrm{L} \mathrm{cm}^{-2}\right)$ obtidos nas folhas da alface-d'água não foram afetados significativamente pela presença do aguapé quando a pulverização da calda foi realizada através da ponta TXVK-8, uma vez que os depósitos médios obtidos nas diferentes associações (inclusive a associação tripla) foram estatisticamente semelhantes aos depósitos obtidos na condição de dominância total de alface-d'água $(100 \%)$.

Quanto à ponta TXVK-8, os depósitos unitários de calda de pulverização obtidos nas associações onde as plantas de salvínia foram utilizadas em maiores proporções (50\% e $75 \%$ ) foram estatisticamente superiores aos demais depósitos.

Efeitos similares da associação da alfaced'água com plantas de aguapé ou salvínia também foram observados quando a pulverização da calda foi realizada pela ponta DG $11002 \mathrm{VS}$. Novamente, os depósitos unitários foram estatisticamente superiores nas proporções onde a salvínia foi utilizada a $50 \%$ e $75 \%$, enquanto todas as demais proporções não diferiram estatisticamente entre si.

Observando-se infestações de aguapé em diferentes locais, é possivel verificar que regiões periféricas das reboleiras apresentam plantas flutuantes mais jovens e, por

Tabela 3 - Valores médios dos depósitos unitários de calda de pulverização observados nas plantas de Pistia stratiotes em função das diferentes proporções de Eichhornia crassipes e Salvinia auriculata. Botucatu-SP, 2004

\begin{tabular}{|c|c|c|c|}
\hline \multirow[t]{2}{*}{ Associação } & \multirow[t]{2}{*}{ Proporção (\%) } & \multicolumn{2}{|c|}{$\begin{array}{l}\text { Depósitos unitários } \\
\qquad\left(\mathrm{L} \mathrm{cm}^{-2}\right)\end{array}$} \\
\hline & & TXVK-8 & DG110.02VS \\
\hline Alface-d'água & 100 & $0,7295 \mathrm{Ca}$ & $0,6006 \mathrm{Bca}$ \\
\hline Alface-d'água/aguapé & $75 / 25$ & $0,7201 \mathrm{Ca}$ & $0,5713 \mathrm{Ca}$ \\
\hline Alface-d'água/aguapé & $50 / 50$ & $0,7749 \mathrm{BCa}$ & $0,5585 \mathrm{Cb}$ \\
\hline Alface-d'água/aguapé & $25 / 75$ & $0,5054 \mathrm{Ca}$ & $0,4971 \mathrm{Ca}$ \\
\hline Alface-d'água/salvínia & $75 / 25$ & $0,6266 \mathrm{Ca}$ & $0,5537 \mathrm{Ca}$ \\
\hline Alface-d'água/salvínia & $50 / 50$ & $1,1976 \mathrm{Aa}$ & $1,0478 \mathrm{Aa}$ \\
\hline Alface-d'água/salvínia & $25 / 75$ & $1,0405 \mathrm{ABa}$ & $0,8935 \mathrm{ABa}$ \\
\hline A. d'água/aguapé/salvinia & $33,3 / 33,3 / 33,3$ & $0,6091 \mathrm{Ca}$ & $0,4794 \mathrm{Ca}$ \\
\hline F Proporção & \multicolumn{3}{|c|}{$20,08 * *$} \\
\hline F Ponta & \multicolumn{3}{|c|}{$13,37^{* *}$} \\
\hline F Proporção x Ponta & \multicolumn{3}{|c|}{$0,40^{*}$} \\
\hline DMS Proporção & \multicolumn{3}{|c|}{0,3070} \\
\hline DMS Ponta & \multicolumn{3}{|c|}{0,1948} \\
\hline CV $(\%)$ & \multicolumn{3}{|c|}{19,22} \\
\hline
\end{tabular}

** Significativo a $1 \%$ de probabilidade; $*$ significativo a $5 \%$ de probabilidade. Médias seguidas de mesma letra maiúscula na coluna e minúscula na linha, não diferem estatisticamente entre si pelo teste de Tukey $(\mathrm{p}>0,05)$. 
conseguinte, pulvinos e folhas dispostas em posições próximas à horizontal. Já plantas localizadas no centro das populações apresentam o pulvino estiolado (não inflado) e, juntamente com o limbo foliar, disposto em uma posição mais próxima à vertical (Marchi et al., 2005b). Esta última forma de arquitetura é típica de plantas mais velhas, de populações mais densas e que se encontram estacionadas ou ancoradas em um mesmo local durante longos períodos. Assumindo uma arquitetura vertical, as folhas tendem a posicionar seus limbos em direção única devido à ação de ventos e, consequentemente, conseguem se dispersar a partir do ponto onde estavam estacionadas ou ancoradas (Holm et al., 1991).

Além da dispersão de plantas, a arquitetura de folhas e pulvinos pode ainda influenciar a quantidade dos depósitos de calda de pulverização sobre plantas de aguapé e outras espécies vizinhas, uma vez que a posição do limbo foliar em relação à direção do jato de pulverização pode favorecer ou mesmo prejudicar o contato entre a gota e a superficie foliar (Marchi et al., 2005b). Nesse caso, o período de sete dias em que as plantas conviveram no mesmo ambiente provavelmente não foi suficiente para alterar a arquitetura foliar do aguapé e, consequentemente, propiciou semelhantes depósitos unitários e totais de calda sobre plantas de alface-d'água.

Na Tabela 4, pode-se notar que os depósitos totais de calda de pulverização ( $\mu \mathrm{L}$ por planta) obtidos onde $25 \%$ de plantas de alface-d'água estiveram associadas com $75 \%$ de plantas de salvinia foram significativamente superiores aos depósitos observados em todas as demais proporções estudadas, independentemente da espécie e do tipo de ponta de pulverização utilizada.

Os maiores depósitos totais de calda verificados nas associações com predominio populacional de salvinia provavelmente se deveram ao isolamento das plantas de alfaced'água e, por conseguinte, à maior individualização no espaço. Devido ao seu hábito de crescimento, o aumento da quantidade de plantas de salvínia na associação proporcionou acúmulo de área foliar na região próxima à superfície de água; embora houvesse alta densidade de plantas de salvínia, o isolamento das plantas de alface-d'água dentro do espaço
Tabela 4 - Valores médios dos depósitos totais de calda de pulverização observados nas plantas de Pistia stratiotes em função das diferentes proporções de Eichhornia crassipes e Salvinia auriculata. BotucatuSP, 2004

\begin{tabular}{|l|c|c|c|}
\hline \multirow{2}{*}{ Associação } & \multirow{2}{*}{ Proporção (\%) } & \multicolumn{2}{c|}{$\begin{array}{c}\text { Depósitos totais } \\
\text { ( L por planta) }\end{array}$} \\
\cline { 3 - 4 } & & TXVK-8 & DG110.02VS \\
\hline Alface-d'água & 100 & $61,79 \mathrm{Ba}$ & $51,10 \mathrm{Ba}$ \\
\hline Alface-d'água/aguapé & $75 / 25$ & $74,28 \mathrm{Ba}$ & $57,93 \mathrm{Ba}$ \\
\hline Alface-d'água/aguapé & $50 / 50$ & $80,54 \mathrm{Ba}$ & $56,79 \mathrm{Bb}$ \\
\hline Alface-d'água/aguapé & $25 / 75$ & $59,05 \mathrm{Ba}$ & $53,37 \mathrm{Ba}$ \\
\hline Alface-d'água/salvínia & $75 / 25$ & $71,10 \mathrm{Ba}$ & $66,12 \mathrm{Ba}$ \\
\hline Alface-d'água/salvínia & $50 / 50$ & $74,12 \mathrm{Ba}$ & $63,85 \mathrm{Ba}$ \\
\hline Alface-d'água/salvínia & $25 / 75$ & $118,59 \mathrm{Aa}$ & $91,45 \mathrm{Ab}$ \\
\hline A. d'água/aguapé/salvinia & $33,3 / 33,3 / 33,3$ & $68,52 \mathrm{Ba}$ & $55,06 \mathrm{Ba}$ \\
\hline F Proporção & \multicolumn{3}{|c|}{$7,49 * *$} \\
\hline F Ponta & \multicolumn{3}{|c|}{$24,30^{* *}$} \\
\hline F Proporção x Ponta & \multicolumn{3}{|c|}{$22,76 * 3$} \\
\hline DMS Proporção & \multicolumn{3}{|c|}{23,21} \\
\hline DMS Ponta & &
\end{tabular}

** Significativo a $1 \%$ de probabilidade; $*$ significativo a $5 \%$ de probabilidade. Médias seguidas de mesma letra, maiúscula na coluna e minúscula na linha, não diferem estatisticamente entre si pelo teste de Tukey $(\mathrm{p}>0,05)$.

foi possível devido ao diferencial de posição na vertical entre folhas de salvinia e alfaced’água.

Martins et al. (2005) verificaram que a adição de adjuvante na calda pulverizada pela ponta tipo leque XR 11002VS proporcionou depósitos nas folhas de alface-d'água estatisticamente semelhantes aos da calda testemunha sem adição de adjuvante. Os valores médios dos depósitos unitários de calda de pulverização obtidos pela adição de $0,25 \%$ e $0,5 \%$ do Aterbane foram de 0,62 e 0,61 $\mu \mathrm{L} \mathrm{cm}^{-2}$, respectivamente, enquanto os depósitos unitários para a calda de pulverização sem adjuvante foram de $0,63 \mu \mathrm{L} \mathrm{cm}^{-2}$.

Neste estudo, os valores médios dos depósitos unitários de calda de pulverização, em $\mu \mathrm{L} \mathrm{cm}^{2}$, em ambas as pontas de pulverização foram relativamente superiores àqueles citados por Martins et al. (2005), principalmente nas associações entre plantas de alface-d'água e salvínia. Além disso, os acréscimos nos depósitos de calda de pulverização observados provavelmente não são devidos exclusivamente ao aumento da proporção de plantas de 
salvínia na associação, e sim à diminuição da quantidade de plantas de alface-d'água e consequente diminuição da cobertura entre as folhas desta espécie, conforme mencionado anteriormente. Isso indica que plantas de alface-d'água individualizadas no ambiente aquático ou plantas localizadas nas bordaduras poderiam receber maior quantidade de produto do que aquelas localizadas no centro das reboleiras.

Somente os depósitos unitários e totais de calda de pulverização proporcionados pela ponta TXVK-8 na associação de $50 \%$ de alfaced'água com 50\% de aguapé (Tabelas 3 e 4) e os depósitos totais na proporção de $25 \%$ de alface-d'água com $75 \%$ de salvínia (Tabela 4) foram significativamente superiores àqueles proporcionados pela ponta DG 11002VS. Cabe salientar que os depósitos unitários e totais de calda de pulverização proporcionados pela ponta TXVK-8 sempre foram numericamente superiores àqueles proporcionados pela ponta DG $11002 \mathrm{VS}$, independentemente da proporção e da espécie envolvida na associação.

No entanto, considerando apenas o fator tipo de ponta de pulverização, verifica-se na Tabela 5 que os depósitos unitários e totais de calda observados para a ponta TXVK-8 foram significativamente superiores quando comparados à ponta DG 11002VS. Já Maciel et al. (2000) e Carbonari et al. (2005), ao estudarem a deposição de calda sobre plantas de Brachiaria decumbens e Cynodon dactilon, respectivamente, observaram que pontas de jato cone proporcionaram maiores deposições

Tabela 5 - Valores médios dos depósitos unitários e totais de calda de pulverização observados nas plantas de Pistia stratiotes em função dos diferentes tipos de ponta de pulverização. Botucatu-SP, 2004

\begin{tabular}{|l|c|c|}
\hline \multirow{2}{*}{ Ponta } & \multicolumn{2}{|c|}{ Depósitos } \\
\cline { 2 - 3 } & Unitários $\left(\mathrm{L} \mathrm{cm}^{-2}\right)$ & Totais ( L por planta) \\
\hline TXVK-8 & $0,7755 \mathrm{a}$ & $76,00 \mathrm{a}$ \\
\hline DG 11002VS & $0,6502 \mathrm{~b}$ & $61,96 \mathrm{~b}$ \\
\hline F Ponta & $13,37 * *$ & $12,30^{* *}$ \\
\hline DMS Ponta & 0,0689 & 8,05 \\
\hline CV $(\%)$ & 19,22 & 23,21 \\
\hline
\end{tabular}

** Significativo a $1 \%$ de probabilidade. Médias seguidas de mesma letra, na coluna, não diferem estatisticamente entre si pelo teste de Tukey $(\mathrm{p}>0,05)$ quando comparadas com pontas de jato leque. Essa divergência entre autores demonstra que a espécie-alvo também pode ser determinante na obtenção dos resultados e que, no caso de Pistia stratiotes, pontas do tipo cone provavelmente sejam mais eficientes quanto à deposição de calda de pulverização em populações que contêm esta espécie.

Esses resultados podem trazer relevantes contribuições caso o manejo de uma população de plantas aquáticas, no qual haja predomínio de plantas de salvínia ou de aguapé, seja preferencialmente realizado com herbicidas. A eficácia do tratamento herbicida sobre plantas de alface-d'água poderá ser influenciada pela menor deposição de calda de pulverização em função do tipo de ponta de pulverização utilizada ou mesmo naquelas situações ou reboleiras onde ocorrem maiores densidades de plantas de aguapé.

\section{AGRADECIMENTOS}

À CAPES - Coordenação de Aperfeiçoamento de Pessoal de Nivel Superior, pela concessão de bolsa de estudos e apoio financeiro a este projeto.

\section{LITERATURA CITADA}

CARBONARI, C. A. et al. Efeito de surfatantes e pontas de pulverização na deposição de calda de pulverização em plantas de grama-seda. Planta Daninha, v. 23, n. 4, p. $725-729,2005$.

CARVALHO, F. T. et al. Plantas aquáticas e nível de infestação das espécies presentes no reservatório de Barra Bonita, no rio Tietê. Planta Daninha, v. 21, p. 15-19, 2003. Edição Especial.

CARVALHO, F. T. et al. Plantas aquáticas e nível de infestação das espécies presentes no reservatório de Bariri, no rio Tietê. Planta Daninha, v. 23, n. 2, p. 371-374, 2005.

CAVENAGHI, A. L. et al. Monitoramento de problemas com plantas aquáticas e caracterização da qualidade de água e sedimento na UHE Mogi-Guaçu. Planta Daninha, v. 23, n. 2, p. 225-231, 2005.

FAIRCHILD, J. F. et al. Efficacy of glyphosate and five surfactants for controlling giand salvinia. J. Aquatic Plant Manag., v. 40, n. 1, p. 53-57, 2002

GERARD, A. J. M. et al. Towards predicting pesticide deposition from plant phenology; a study in spring barley. Pestic. Sci., v. 53, n. 3, p. 252-262, 1998.

Planta Daninha, Viçosa-MG, v. 27, n. 2, p. 389-396, 2009 
HOLM, L. G. et al. The world's worst weeds. Malabar: Krieger Publishing Company, 1991. 609 p

JOYLE, J. C.; SIKKA, H. C. Residual 2,4-D levels in the St Johns River, Florida. J. Aquatic Plant Manag., v. 15, n. 2 , p. $72-82,1977$.

KISSMANN, K.; GROTH, D. Plantas infestantes e nocivas. 2.ed. São Paulo: BASF Brasileira, 1997. Tomo I. $824 \mathrm{p}$

KOSCHNICK, T. J. et al. Carfentrazone-ethyl pond dissipation and efficacy of floating plants. J. Aquatic Plant Manag., v. 42, n. 2, p. 103-108, 2004.

LINDGREN, C. J. et al. Compatibility of glyphosate with Galerucella calmariensis: A biological control agent for purple loosestrife (Lythrum salicaria). J. Aquatic Plant Manag., v. 37, n. 2 , p. $44-48,1999$.

MACIEL, C. D. G. et al. Depósito e distribuição de calda de pulverização em plantas de feijoeiro e capim-braquiária. Planta Daninha, v. 19, n. 1, p. 103-117, 2000.

MARCHI, S. R. et al. Estimativa da área foliar de plantas daninhas de ambiente aquático: Pistia stratiotes. In: CONGRESSO BRASILEIRO DA CIÊNCIA DAS PLANTAS DANINHAS, 24., 2004, São Pedro. Resumo expandido... São Pedro: Sociedade Brasileira da Ciência das Plantas Daninhas, 2004. CD ROM.

MARCHI, S. R. et al. Degradação luminosa e retenção foliar dos corantes Azul Brilhante FDC-1 e Amarelo Tartrasina FDC-5 utilizados como traçadores em pulverizações. Planta Daninha, v. 23, n. 2, p. 287-294, 2005a.

MARCHI, S. R. et al. Depósitos de calda de pulverização nas faces adaxial e abaxial de folhas de Eichhornia crassipes dispostas em diferentes ângulos. Planta Daninha, v. 23, n. 2 , p. $321-328,2005$ b.

MARTINS, D. et al. Controle químico de plantas daninhas aquáticas em condições controladas - caixa d'água. Planta Daninha, v. 17, n. 2, p. 289-296, 1999.

MARTINS, D. et al. Controle químico de Pistia stratiotes, Eichhornia crassipes e Salvinia molesta em caixas d'água. Planta Daninha, v. 20, p. 83-88, 2002. Edição Especial.
MARTINS, D. et al. Ocorrência de plantas aquáticas nos reservatórios da Light-RJ. Planta Daninha, v. 21, p. 105-108, 2003. Edição Especial.

MARTINS, D. et al. Efeito de diferentes concentrações de Aterbane na deposição de calda em plantas de Pistia stratiotes. Planta Daninha, v. 23, n. 2, p. 343-348, 2005.

NELSON, L.S.; SHEARER, J. F. 2,4-D and Mycoleptodiscus terrestris for control of eurasian watermilfoil. J. Aquatic Plant Manag., v. 43, n. 1, p. 29-33, 2005.

NEVES, T.; FOLONI, L. L.; PITELLI, R. A. Controle químico do aguapé (Eichhornia crassipes). Planta Daninha, v. 20, p. 89-97, 2002. Edição Especial.

PALLADINI, L. A. Metodologia para avaliação da deposição em pulverizações. 2000. 111 f. Tese (Doutorado em Agronomia) - Universidade Estadual Paulista "Julio Mesquita Filho", Botucatu, 2000.

RICHARDSON, B.; NEWTON, M. Spray deposition within plant canopies. New Zealand Plant Protec., v. 53 , p. $248-252,2000$.

SELVAN, R. P.; LALL, M. Chemical control of water hyacinth. In: ANNUAL CONFERENCE OF INDIAN SOCIETY OF WEED SCIENCE, 1981, Oxford. Proceedings... Oxford: 1981. p. 141-148.

SOUZA, R. T.; VELINI, E. D.; PALLADINI, L. A. Aspectos metodológicos para análise de depósitos de pulverizações para determinação dos depósitos pontuais. Planta Daninha, v. 25, n. 1, p. 195-2002, 2007.

SPILLMAN, J. J. Spray impaction, retention and adhesion: an introduction to basic characteristics. Pestic. Sci., v. 15, n. 1, p. $97-106,1984$

TANAKA, R. H. et al. Ocorrência de plantas daninhas nos reservatórios da Companhia Energética de São Paulo. Planta Daninha, v. 20, p. 101-111, 2002. Edição Especial.

VAN, T. K. et al. Effects of herbicides rate and carrier volume on glyphosate phytotoxity. J. Aquatic Plant Manag., v. 4, n. 1, p. $66-89,1987$

WIRTH, W.; STORP, S.; JACOBENSEN, W. Mechanisms controlling leaf retention of agricultural spray conditions

Pestic. Sci., v. 33, n. 4, p. 411-420, 1991. 